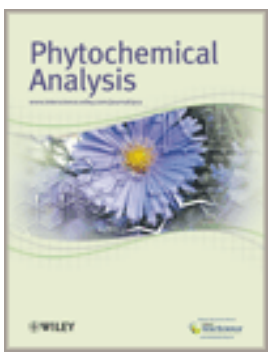

\title{
Phytochemical fingerprinting of vegetable Brassica oleracea and Brassica napus by simultaneous identification of glucosinolates and phenolics
}

\begin{tabular}{|c|c|}
\hline Journal: & Phytochemical Analysis \\
\hline Manuscript ID: & Draft \\
\hline Wiley - Manuscript type: & Research Article \\
\hline \multicolumn{2}{|l|}{$\begin{array}{l}\text { Date Submitted by the } \\
\text { Author: }\end{array}$} \\
\hline Complete List of Authors: & $\begin{array}{l}\text { Velasco, Pablo; Misión Biológica de Galicia (CSIC), Plant Genetics } \\
\text { Francisco, Marta } \\
\text { Moreno, Diego } \\
\text { Ferreres, Federico } \\
\text { Garcia-Viguera, Cristina } \\
\text { Cartea, Elena; Mision Biologica de Galicia (CSIC), Plant Genetics }\end{array}$ \\
\hline Keywords: & $\begin{array}{l}\text { Brassica oleracea, Brassica napus, glucosinolates, phenolic } \\
\text { compounds, LC/UV-PAD/ESI-MSn }\end{array}$ \\
\hline
\end{tabular}

\section{ScholaroNE" \\ Manuscript Central}


1 Phytochemical fingerprinting of vegetable Brassica oleracea and Brassica napus by

2 simultaneous identification of glucosinolates and phenolics

3

4 Pablo Velasco $^{\mathrm{a} *}$, Marta Francisco ${ }^{\mathrm{a}}$, Diego A. Moreno ${ }^{\mathrm{b}}$, Federico Ferreres $^{\mathrm{b}}$, Cristina García5 Viguera $^{\mathrm{b}}$, María Elena Cartea ${ }^{\mathrm{a}}$

6

7 a. Misión Biológica de Galicia (CSIC), PO Box 28, E-36080 Pontevedra, Spain

8 b. Department of Food Science and Technology, CEBAS-CSIC, Campus Universitario de

9 Espinardo-Edificio 25, PO Box 164, Espinardo, E-30100 Murcia, Spain

$10 *$ Corresponding author:

11 Pablo Velasco

12 Address: Misión Biológica de Galicia (CSIC), PO Box 28, E-36080· Pontevedra, Spain

13 Tel: 0034-986854800

14 Fax: 0034-986841362

15 E-mail: pvelasco@mbg.cesga.es

17 Abstract

18 For the first time, intact glucosinolates and phenolic compounds were simultaneously

19 identified in kale, cabbage and leaf rape by LC-UV (PAD)-(ESI) MSn. This study led to the 20 identification of 12 glucosinolates and 32 phenolic compounds which included quinic acid 21 esters of hydroxycinnamic acids, hydroxycinnamic acyl gentobiosides and flavonoids. This 22 study provided a deeper and complete identification of health-promoting compounds in kale 23 and cabbage than previously reported and the new identification of the major phenolic 24 compounds in leaf rape. 
25 KEYWORDS: Brassica oleracea, Brassica napus, glucosinolates, phenolic compounds,

26 flavonol glycosides, hydroxycinnamic acids, LC/UV-PAD/ESI-MSn

27 


\section{INTRODUCTION}

29 Brassica vegetables have been related with the prevention of degenerative diseases and

30 different types of cancer as well as cardiovascular health-promotion (Cartea and Velasco,

31 2008; Traka and Mithen, 2009). Compounds that appear to contribute to these health-related

32 properties of brassicas and other food plants include isothiocyanates and their cognate

33 glucosinolates, phenolics, including flavonoids, and other non-nutrients (Jahangir et al., 2009;

34 Jeffery and Araya, 2009) inducing a variety of physiological functions as direct or indirect

35 antioxidants, regulation of enzyme proteins and activities and controlling apoptosis and cell

36 cycle (Duthie et al., 2000).

37 Glucosinolates are a large group of sulphur-containing secondary plant metabolites, which

38 occur in all Brassica crops. A wide variety of glucosinolates exists but all share a common

39 structure comprises a $\beta$-thioglucoside $\mathrm{N}$-hydroxysulfates, a $\beta$-D glucopyranosyl moiety and a

40 variable side-chain derived from methionine, tryptophan or phenylalanine. Upon cellular

41 disruption, glucosinolates are hydrolyzed to various bioactive breakdown products by the

42 endogenous enzyme myrosinase. Isothiocyanates and indole glucosinolate metabolites (in

43 particular indol-3-carbinol) are two major groups of autolytic breakdown products of

44 glucosinolates. Both of them exhibit protective activities against many types of cancer. In

45 vitro and in vivo studies have reported that these compounds may affect many stages of

46 cancer development, including the induction of detoxification enzymes (Phase II enzymes)

47 and the inhibition of activation enzymes (Phase I enzymes) (Mithen et al., 2003) but also

48 antiproliferative mechanisms like cell cycle arrest or apoptosis (Clarke et al., 2008).

49 Phenolic compounds are a large group of phytochemicals widespread in plant kingdom.

50 Depending on their structure they can be classified into simple phenols, phenolic acids,

51 hydroxycinnamic acid derivatives and flavonoids. The most common are the flavonoids

52 which are built upon $\mathrm{C}_{6}-\mathrm{C}_{3}-\mathrm{C}_{6}$ flavone skeleton. Flavonoids and hydroxycinnamic acid 
53 derivatives are widely distributed in plants and are important biologically active constituents

54 of the human diet. In Brassica foods the flavonoids are complex, with up to five sugar

55 residues present, and these may be further substituted with hydroxycinnamic residues (Vallejo

56 et al., 2004). The bioavailability and activity of different glycosides depends on their

57 substituents (Cermak et al., 2003). For this reason, it is important to characterize and quantify

58 the different derivatives of phenolic compounds. These compounds have direct antioxidant

59 and free radical-scavenging activities but can also induce expression of various genes

60 encoding metabolic enzymes thought to decrease the risk of various diseases and disorders

61 (Bennett et al., 2006).

62 The Brassicaceae family has been widely investigated for glucosinolate (Kushad et al., 1999;

63 Padilla et al., 2007c; Cartea et al., 2008a; 2008b) and for phenolic composition (Llorach et al.,

64 2003a; Vallejo et al., 2004; Ferreres et al., 2005; 2006; Romani et al., 2006; Sousa et al.,

65 2008). Nowadays, the profile of different Brassica species is well established. The analysis of

66 these compounds by different methods is laborious and time consuming. Both phenolic

67 compounds and glucosinolates have beneficial properties on human health and synergic

68 effects could appear between both classes of metabolites. For this reason, a method to extract

69 and analyze these compounds at the same time would be very useful. Bennet et al (2003;

70 2006) used a method for analyzing both kinds of compounds on different species. Later, this

71 method was applied to a set of turnip green and turnip top local populations (B. rapa var.

72 rapa) (Francisco et al., 2009) but, as far as we know, the method has not been used for other

73 Brassica crops, like B. oleracea acephala and capitata groups, and B. napus.

74 In Galicia (northwestern Spain), different Brassica species are used as leaf vegetable products

75 for human and also for animal consumption. Kales (Brassica oleracea acephala group),

76 cabbages (B. oleracea capitata group), leaf rape (B. napus pabularia group), and turnip tops

77 and turnip greens (B. rapa rapa group) are the most important Brassica crops in this region. 
78 At the Misión Biológica de Galicia (CSIC, Spain), a collection of local varieties of $B$.

79 oleracea and B. napus is kept as part of the Brassica genus germplasm bank. In previous

80 reports, this collection was characterized based on morphological and agronomical traits

81 (Picoaga et al., 2003; Rodriguez et al., 2005; Padilla et al., 2007a; Soengas et al., 2008; Vilar

82 et al., 2008) and the profile of desulphoglucosinolates in leaves was studied (Cartea et al.,

83 2008a; 2008b; Velasco et al., 2008). To date, no information is available on content of intact

84 glucosinolates and phenolic compounds in these species. Therefore, for a more

85 comprehensive assessment that allows the nutritional study, the objective of this work was the

86 identification of glucosinolates, flavonoids and hydroxycinnamic acids in a representative

87 variety of kale, cabbage and leaf rape. Identification was carried out by LC-UV photodiode

88 array detection (PAD)-electrospray ionization (ESI) MSn. 
EXPERIMENTAL

90 Plant material. One local variety of each crop was evaluated in this study: a kale variety

91 named as 'MBG-BRS0468' (B. oleracea acephala), a white cabbage variety named as 'MBG-

BRS0057' (B. oleracea capitata), and a leaf rape variety named as 'MBG-BRS0063' (B. napus pabularia). These varieties are in the germplasm collection at the Misión Biológica de

94 Galicia (CSIC) and were selected based on previous agronomic and nutritional evaluations 95 (Rodriguez et al., 2005; Cartea et al., 2008a; 2008b; Soengas et al., 2008; Vilar et al., 2008). The populations were planted in multipot-trays and seedlings were transplanted into the field

97 at the five or six leaves stage to collect leaves in well-developed plants. After harvesting on dry ice, the material was immediately transferred to the laboratory and frozen at $-80^{\circ} \mathrm{C}$, prior to their lyophilisation. The dried material was powdered using an IKA-A10 (IKA-Werke $\mathrm{GmbH} \& \mathrm{Co.KG)}$ mill and the powder was used for analysis.

101

102

Sample preparation. Extraction and the LC gradient for glucosinolate and phenolic analyses

103 is a multi-purpose chromatographic method that simultaneously separates glucosinolates and 104 phenolics (Bennett et al., 2003; 2006). Fifty mg of each sample were extracted in $1.5 \mathrm{~mL} 70 \%$ $\mathrm{MeOH}$ at $70^{\circ} \mathrm{C}$ for $30 \mathrm{~min}$ with vortex mixing every $5 \mathrm{~min}$ to facilitate the extraction. The 106 samples were centrifuged $\left(13000 \mathrm{~g}, 15 \mathrm{~min}, 4^{\circ} \mathrm{C}\right)$. The supernatants were collected and methanol was completely removed using a rotary evaporator under vacuum at $37^{\circ} \mathrm{C}$. The dry material obtained was redissolved in $1 \mathrm{~mL}$ of ultrapure water and filtered through a $0.20 \mu \mathrm{m}$ syringe PTFE filters (Anotop ${ }^{\mathrm{TM}}$, Whatman International Ltd, UK).

Alkaline hydrolysis. For the study of acyl flavonoid derivatives, an alkaline hydrolysis was carried out to eliminate acid moieties like p-coumaroyl $(\mathrm{m} / \mathrm{z}, 146)$ and caffeoyl $(\mathrm{m} / \mathrm{z}, 162)$,

113 which coincide with those of rhamnosyl and hexosyl residues respectively and, therefore, a 
114 miss-assignation can occur in MS analysis. Saponification was performed as follows: $1 \mathrm{~mL}$ of 115 the extract plus $1 \mathrm{~mL}$ of $2 \mathrm{M} \mathrm{NaOH}$ (up to $\mathrm{pH} 9-10$ ) for $12 \mathrm{~h}$ at room temperature in a 116 stoppered test tube under $\mathrm{N}_{2}$ atmosphere. The alkaline hydrolysis products were acidified with concentrated $\mathrm{HCl}$ (up to $\mathrm{pH} 1-2$ ) and directly analysed by LC/UV- PAD/ESI-MSn.

119 LC/UV- PAD/ESI-MSn analyses. Chromatographic analyses were carried out on a Luna 120 C18 column $(250 \mathrm{~mm} \times 4.6 \mathrm{~mm}, 5 \mu \mathrm{m}$ particle size; Phenomenex, Macclesfield, UK). The 121 mobile phase was a mixture of (A) Trifluoro acetic acid (TFA) $0.1 \%$ and (B) acetonitrile/TFA (99.9:0.1). The flow rate was $1 \mathrm{~mL} \mathrm{~min}^{-1}$ in a linear gradient starting with $0 \% \mathrm{~B}$ at $0-5 \mathrm{~min}$, and $227 \mathrm{~nm}$ for glucosinolates. The LC/UV- PAD/ESI-MSn analyses were carried out in an Agilent HPLC 1100 series equipped with a photodiode array detector and mass detector in series (Agilent Technologies, Waldbronn, Germany). The HPLC consisted of a binary pump (model G1312A), an autosampler (model G1313A), a degasser (model G1322A), and a photodiode array detector (model G1315B). The HPLC system was controlled by a ChemStation software (Agilent, v. 08.03). The mass detector was an ion trap spectrometer (model G2445A) equipped with an electrospray ionisation interface and was controlled by LCMSD software (Agilent, v. 4.1). The ionisation conditions were adjusted at $350^{\circ} \mathrm{C}$ and $4 \mathrm{kV}$ 134 for capillary temperature and voltage, respectively. The nebulizer pressure and flow rate of 135 nitrogen were $65.0 \mathrm{psi}$ and $11 \mathrm{~L} \mathrm{~min}^{-1}$, respectively. The full scan mass covered the range 136 from $\mathrm{m} / \mathrm{z}, 100$ up to $\mathrm{m} / \mathrm{z}$ 1500. Collision-induced fragmentation experiments were performed 137 in the ion trap using helium as the collision gas, with voltage ramping cycles from 0.3 up to 2 
138 V. Mass spectrometry data were acquired in the negative ionisation mode. MSn is carried out 139 in the automatic mode on the more abundant fragment ion in MS(n-1).

140 


\section{RESULTS AND DISCUSSION}

\section{Glucosinolate identification.}

143 The MS product ions obtained from glucosinolates were dominated by intense $[\mathrm{M}-\mathrm{H}]$-ions

144 and other fragments of the composition of the side chain. Glucosinolates fragmentation

145 revealed two groups of typical fragments, one associated with the common moiety of the

146 glucosinolates (aglycone) and the other providing useful diagnostic ions for the identification

147 of the variable side chain. As it has been described by other authors (Fabre et al., 2007;

148 Rochfort et al., 2008), the $\mathrm{MS}^{2}$ fragmentation of the aglycone side chain produces specific

149 ions at $m / z, 195,241,259$ and 275. The fragmentation of the ion $m / z 259\left(\mathrm{MS}^{3}[(\mathrm{M}-\mathrm{H}) \rightarrow 259]^{-}\right.$

150 ) gave rise to the fragments at $m / z, 139,97$ (corresponding to the sulphate group $\left(\left[\mathrm{SO}_{4} \mathrm{H}\right]^{-}\right)$),

151 and $m / z 81\left(\left[\mathrm{SO}_{3} \mathrm{H}\right]^{-}\right)$. The $m / z, 97$ fragment ion is formed with high abundance in negative

152 ion ESI method (Mellon et al., 2002). Therefore fragments at $\mathrm{m} / \mathrm{z}, 259$ and $\mathrm{m} / \mathrm{z}, 97$ were used as

153 diagnostic ions of glucosinolates. These fragment ions were a very useful preliminary

154 screening method for determining the presence of glucosinolates in plant extracts.

155 The other group of fragments are compound-specific products ions that allowed structure

156 elucidation. All glucosinolates provided of constant neutral loss under the fragmentation

157 conditions. The most intense and consistent was the combined loss of sulphur trioxide and

158 anhydroglucose [M-H-242] $]^{-}$Other MS fragmentation pathways were to losses of glucose

159 radical $[\mathrm{M}-\mathrm{H}-162]^{-}$and/or thioglucose moiety $[\mathrm{M}-\mathrm{H}-196]^{-}$after the H-rearrangement of the

160 side chain to the sulphur atom in thioglucose moiety (Kokkonen et al., 1991). The indolic

161 glucosinolates were characterized also by the examination of characteristic product ions from

162 their specific R. This group contain two nitrogen atoms and the $m / z$ values of their

163 deprotonated molecules were thus at odd mass numbers. Neoglucobrassicin and 4-

164 methoxyglucobrassicin exhibit identical molecular masses and fragmentation ions, they were 
165 differentiated by comparison with reported elution sequence during reversed phase HPLC

166 (Kushad et al., 1999).

167 Therefore the molecular ion $[\mathrm{M}-\mathrm{H}]^{-}$of glucosinolates, their fragment ion pattern and the

168 retention times allowed the identification of eight glucosinolates in kale and cabbage which 169 exhibited the same glucosinolate profile and eleven glucosinolates in B. napus (Figure 1). In 170 total were identified the following intact glucosinolates: $\mathrm{m} / \mathrm{z} 422$ glucoiberin, $\mathrm{m} / \mathrm{z} 388$ 171 progoitrin, $m / z 358$ sinigrin, $m / z, 438$ glucoraphanin, $m / z, 402$ gluconapoleiferin, $m / z 372$ 172 gluconapin, $\mathrm{m} / \mathrm{z} 463$ 4-hydroxyglucobrassicin, $\mathrm{m} / \mathrm{z} 386$ glucobrassicanapin, $\mathrm{m} / \mathrm{z} 447$ 173 glucobrassicin, $\mathrm{m} / \mathrm{z} 422$ gluconasturtiin, $\mathrm{m} / \mathrm{z} 477$ 4-methoxyglucobrassicin and $\mathrm{m} / \mathrm{z} 477$ 174 neoglucobrassicin. The mass spectral information of the glucosinolates identified is 175 summarized in Table 1. The GS profile found in these three crops was similar to those 176 reported by other authors in B. oleracea and B. napus leaves (Cartea et al., 2008a; 2008b).

177 Cartea et al. (Cartea et al., 2008a; 2008b) studied the glucosinolate content of the collection of 178 kale, cabbage and leaf rape kept at the MBG by HPLC-DAD and some differences were 179 found regarding the current work. Eight glucosinolates were identified in the B. napus 180 collection by HPLC-DAD. In the present work, 4-methoxyglucobrassicin was not detected 181 and four other glucosinolates (4-hydroxyglucobrassicin, glucoiberin, sinigrin and 182 glucoraphanin) were also identified although all of them in trace quantities (Table 1, Fig.1). 183 With regard to kales and cabbages, the same authors found and quantified 10 and 15 184 glucosinolates, respectively (Cartea et al., 2008a; 2008b). In this work, the most abundant 185 glucosinolates (i.e. glucoiberin, sinigrin, or glucobrassicin) were identified in both crops but 186 other minor glucosinolates like progoitrin, glucoiberverin, glucoalyssin, and 187 glucobrassicanapin, were not found in kale and cabbage (Table 1, Fig.1). 
190 The HPLC-DAD chromatogram of Brassica vegetable extracts revealed the existence of 191 glycosylated derivatives of three flavonoids with substitution in position 3, that is, kaempferol $192(267,300 \mathrm{sh}$ and $349 \mathrm{~nm})$, quercetin $(255,267 \mathrm{sh}$, and $355 \mathrm{~nm})$ and isorhamnetin $(255,268 \mathrm{sh}$, $193294 \mathrm{sh}$, and $354 \mathrm{~nm}$ ). In addition, acylated flavonoids were detected in the extract, and their 194 UV spectra, characterized with a maximum with a high absorption at $330 \mathrm{~nm}$ and a little 195 maximum between 255 and $268 \mathrm{~nm}$, suggested that the flavonoid-glycoside molecules were 196 linked with hydroxycinnamic acid derivatives, in which sinapic, ferulic, caffeic and $p$ 197 coumaric acids were the most abundant. The results are summarized in Table 2 . The 198 chromatographic profiles, recorded at $330 \mathrm{~nm}$, of the naturally occurring phenolic compounds 199 in leaf rape, kale and cabbage extracts and the deacylated phenolic compounds, obtained after 200 alkaline hydrolysis, are shown in (Fig. 2).

201 Alkaline hydrolysis was performed to reduce the complexity of the naturally occurring 202 compounds present in the plant extracts due to the release of the hydroxycinnamic acids by 203 cleavage of the ester linkage between the acids and the glycosides (Martens, 2002). After 204 alkaline hydrolysis, the chromatogram showed, apart from several hydroxycinnamic acids, 205 various flavonoid glycosides and disappearance of the acylated derivatives (Fig. 2).

206 Deacylated flavonoids.

207 The MS ion trap analysis of the saponified extracts of the leaves showed mainly the presence 208 of several kaempferol derivatives but quercetin and isorhamnetin were also determined. The 209 presence of the ion at $m / z, 285 / 284[\mathrm{Agl}-\mathrm{H} / 2 \mathrm{H}]^{-}$as base peak for compounds $\mathbf{2}, \mathbf{3}, \mathbf{4}, \mathbf{7}, \mathbf{8}$ and 9 210 show them as kaempferol derivatives (3,5,7,4'-tetrahydroxyflavone), while on compounds 1 211 and 6 this ion was $m / z 301 / 300$ indicative of quercetin derivatives $\left(\left(3,5,7,3^{\prime}, 4^{\prime}-\right.\right.$

212 pentahydroxyflavone pentahydroxyflavone) and $\mathrm{m} / \mathrm{z} 315$ for $\mathbf{5}$ isorhamnetin derivatives 213 (3,5,7,4'-tetrahydroxy-3'-methoxyflavone) (Table 2). The $\mathrm{MS}^{2}[\mathrm{M}-\mathrm{H}]^{-}$fragmentation analysis 214 of compounds 1-5 showed ions [M-H-162] ${ }^{-}$as base peak, indicated a loss of glycosidic 
215 residue at 7 position (Ferreres et al., 2004). According to previous studies (Llorach et al., 216 2003b; Ferreres et al., 2004; Vallejo et al., 2004) the fragmentation pattern and the relative 217 abundance of the obtained ions indicated that compounds 1-3 are glycosylated with a 218 hexoside in position 7 and a di- or trihexoside in the 3 position. The first fragmentation of the 219 deprotonated molecular ion $[\mathrm{M}-\mathrm{H}]^{-}$in this compounds is expected to always be due to the 220 breakdown of the O-glycosidic bond at the 7-position (Ferreres et al., 2004). The remaining 221 glycosyl moieties of the flavonoid molecule are expected to be linked to the hydroxyl at the 3222 position on the flavonol aglycone. The fragmentation $\mathrm{MS}^{3}[(\mathrm{M}-\mathrm{H}) \rightarrow(\mathrm{M}-\mathrm{H}-162)]^{-}$of 1-3 223 showed losses to come from interglycosidic fragmentations at position 3 of the ring which in 224 agree with previous Brassica works, mentioned above, suggest the $(1 \rightarrow 2)$ interglycosidic 225 linkage between the disaccharide moieties of the flavonoids (mainly sophorosides). So, these 226 compounds were tentatively characterized as (1) quercetin-3- $O$-sophoroside-7- $O$-glucoside;

227 (2) kaempferol-3- $O$-sophorotrioside-7- $O$-glucoside and (3) kaempferol-3- $O$-sophoroside-7- $O$ 228 glucoside. Compounds $\mathbf{4}$ and $\mathbf{5}$ were characterized as flavonoids with two sugar moieties 229 linked to different phenolic hydroxyl (di- $O$-glycosidics). According to Ferreres et al. (2004), 230 in these 3,7-di-O-glucosides, a base peak ion at $[\mathrm{M}-\mathrm{H}-162]^{-}$in the $\mathrm{MS}^{2}[\mathrm{M}-\mathrm{H}]^{-}$mode is 231 always observed (Table 2). On the other hand, for compounds 6, 7 and 8 it was observed the 232 fragment ion $[\mathrm{M}-\mathrm{H}-180]^{-}$and the appearance of $[\mathrm{Agl}-\mathrm{H}]^{-}$as base peak in the $\mathrm{MS}^{2}[\mathrm{M}-\mathrm{H}]^{-}$, 233 together with the observed fragmentations, indicating them as flavonol- $O$-diglycosidics. The 234 UV spectra and MS fragmentation for compounds $\mathbf{7}$ and $\mathbf{8}$ show that they are kaempferol-3$235 \quad O$-dihexosides isomers. The $[\mathrm{M}-\mathrm{H}-180]^{-}$ion was not observed in the fragmentation of 7; 236 while this ion is very important for the compound $\mathbf{8}$, indicating a interglycosidic linkage $237(1 \rightarrow 2)$ for this compound. Thus, they were identified as (4) kaempferol-3,7-di- $O$-glucoside; 238 (5) isorhamnetin-3,7-di- $O$-glucoside; (6) quercetin-3- $O$-sophoroside; (7) kaempferol-3-O239 diglucoside; and (8) kaempferol-3-O-sophoroside. Compound 9 was identified as a 
240 monoglycoside kaempferol derivative with hydroxyl at 3 position free: (9) kaempferol-7-O241 glucoside.

242 In native extracts of kale, cabbage and leaf rape we observed compounds previously described 243 by other authors in Brassica spp.(Llorach et al., 2003a; 2003b; Ferreres et al., 2004; Vallejo et 244 al., 2004; Ferreres et al., 2005; 2006). The compound 5 was found only in B. napus extracts in 245 trace quantities.

246 Acylated flavonoids.

247 Several of the flavonoids in the Brassica sample extracts had UV spectra with a broad 248 maximum absorbance around 330-340 $\mathrm{nm}$ (Table 2), suggesting they were acylated with 249 hydroxycinnamic acids (Fig. 2). The comparison of the HPLC-DAD chromatogram of the 250 extracts with that of the saponified extract (Fig.2) indicated the existence of acylated 251 compounds in high amounts. The MS study of these compounds allowed the detection of a 252 total of 13 acylated flavonol glycosides (compounds 10-22). These compounds were acyl 253 derivatives from compounds $1(10,13), 3(11,12,14,15,16,17), 6(21)$ and $8(18,19,20$, 254 22). The fragmentation of some of these acylated derivatives showed in $\mathrm{MS}^{2}$ a base peak 255 resultant from the loss of the sugar in the 7 position $[(\mathrm{M}-\mathrm{H})-162)]^{-}$. This fragmentation is 256 typical from flavonid-3-O-(acyl)glycoside-7- $O$-hexoside and has been widely described in 257 different Brassicas (Llorach et al., 2003a; Ferreres et al., 2005; 2006; 2008). Other important 258 ion also detected was due to the loss of the acyl radical and/or the sugar and acids from the $259[\mathrm{M}-\mathrm{H}]^{-}$. The resulting fragmentation after the loss of the sugar residues at 7 position ($\left.260 \mathrm{MS} 3[(\mathrm{M}-\mathrm{H}) \rightarrow(\mathrm{M}-\mathrm{H}-162)]^{-}\right)$, showed that the acid loss is easily detected and that the acylation 261 is always present on the sugars at 3 position in these compounds. Losses of 162, 206, 176, 262146 and $192 \mathrm{~m} / \mathrm{z}$ has been identified as caffeic acid, sinapic acid, ferulic acid, $p$-coumaric 263 acid and methoxycaffeic, respectively. The ion corresponding to the flavonoid 3-O-glycoside 264 was always the base peak in $\mathrm{MS}^{3}$ of these compounds. Thus, they had been characterized as 
265 acylated derivatives of quercetin-3-O-sophoroside-7-O-glucoside with caffeoyl (10) and 266 sinapoyl (13), and kaempferol-3- $O$-sophoroside-7- $O$-glucoside with methoxycaffeoyl (11), 267 caffeoyl (12 and 17), sinapoyl (14), feruloyl (15) and p-coumparoyl (16). Compounds 18-22 268 presented a fragmentation $\mathrm{MS}^{2}[\mathrm{M}-\mathrm{H}]^{-}$similar to the $\mathrm{MS}^{3}$ of previous compounds (Table 2), 269 what is expected of flavonoids with glycosilation on a single phenolic hydroxyl. In addition 270 an ion resulting from loss of the acyl radical and fragment $m / z, 180(162+18)[(\mathrm{M}-\mathrm{H})$-acyl$\left.2711^{180}\right]^{-}$that comes from the interglycosidic breakdown was observed in the fragmentation of 272 19-22, confirming the structure of flavonoid- $O$-diglycosides. These compounds have been 273 characterized as acyl derivatives of kaempferol-3- $O$-sophoroside with $p$-coumaroyl (18), 274 methoxycaffeoyl (19), caffeoyl (20), sinapoyl (22) and quercetin-3-O-(feruloyl) sophoroside 275 (21).

276

\section{Hydroxycinnamic acids identification.}

278 Ten hydroxycinnamic acids and derivatives (3CQAc, 3pCoQAc, SG, 4CQAc, 4FQAc, SA, 279 A, B. C, and D) were detected in leaves of leaf rape, kale and cabbage (Table 3, Fig. 2). The 280 most abundant in the three crops were 3-caffeoyl quinic acid (3CQAc) $(R \mathrm{t}$ 17.3 min; UV 281 295sh, $325 \mathrm{~nm}$; MS: 353, MS2(353): 191 (100\%), 179 (62\%)), 3-p-coumaroyl quinic acid 282 (3pCoQAc) (Rt $19.1 \mathrm{~min}$; UV $311 \mathrm{~nm}$; MS: 337, MS2(337): 191 (7\%), 179 (100\%)) [30], and 283 sinapoylglucoside (SG) (Rt 20.5 min; UV 329 nm; MS: 285, MS2(285): 291 (100\%), 223 284 (85\%)). 4-caffeoyl quinic (4CQAc) (Rt $19.6 \mathrm{~min}$; UV 295sh, $326 \mathrm{~nm}$; MS: 353, MS2(353): 285191 (16\%), $179(53), 173(100 \%), 191(16), 135(12 \%))$ and 4-feruloyl quinic (4FQAc) (Rt $28622.9 \mathrm{~min} ; \mathrm{UV} 325 \mathrm{~nm}$; MS: 367, MS2(367): 191 (5\%), 173 (3\%), $163(100 \%), 119(5 \%))$

287 were also identified in kale and cabbage but not in leaf rape. Derivatives formed from the 288 interaction of hydroxycinnamic acids with quinic acid and glucose were previously reported 289 in kale, pak choi, Chinese leaf mustard, turnip greens and turnip tops (Rochfort et al., 2006; 
290 Ayaz et al., 2008; Ferreres et al., 2008; Francisco et al., 2009; Olsen et al., 2009). Sinapic acid 291 (SA) (Rt 27.3 min; UV 329 nm; MS: 223, MS2(223): 208 (35\%), 179(30\%), 164(100\%)) was 292 a compound present in high quantities in B. napus and detected in trace amounts in the two $B$. 293 oleracea crops.

294 Other identified hydroxycinnamic acid derivatives were sinapic and ferulic acids esterified 295 carrying more than one hexose moiety (compounds A, B, C and D). It could be observed in 296 all cases, the loss of $224 \mathrm{~m} / \mathrm{z}$ from the deprotonated molecular ion, corresponding to sinapic 297 acid (Table 3). Compound $\mathbf{A}$ and $\mathbf{D}$ also presented ferulic acid and displayed the loss of this 298 acid $(194 \mathrm{~m} / \mathrm{z})$. By comparison with data reported earlier in other Brassicas (Llorach et al., 2992003 b; Ferreres et al., 2006) these compounds were tentatively identified as: 1,2-

300 disinapoylgentiobioside (A), 1-sinapoyl-2-feruloylgentiobioside (B), 1, 2, 2'-

301 trisinapoylgentiobioside (C), and 1,2'-disinapoyl-2-feruloylgentiobioside (D). These results 302 are in accordance with compounds detected in other Brassica species, like turnip tops 303 (Romani et al., 2006; Francisco et al., 2009), tronchuda cabbage (Ferreres et al., 2006) 304 broccoli (Vallejo et al., 2004) and now for first time in kale and leaf rape.

\section{CONCLUCIONS}

307 A method to simultaneously extract and identify glucosinolates and phenolic compounds 308 (Bennett et al., 2003; 2006) is used for first time in B. oleracea acephala and capitata groups 309 and B. napus crops. Twelve intact glucosinolates and 32 phenolic compounds were 310 simultaneously characterized by LC/UV-PAD/ESI-MSn. The major flavonoid kaempferol 311 was found as mono-, di-, and triglycosides acylated with different hydroxycinnamic acids. 312 The major hydroxycinnamic acid derivatives were present as esters of sinapic acid, ferulic 313 acid, and glycosides. The highest difference between species is the number of sugar residues 
314 present on the flavonol core. It may also be expected that the different glycosides possess

315 different biological activities for human health.

316 This study shows that kale, cabbage and leaf rape are a good source of phenolic antioxidants.

317 The main naturally occurring phenolic compounds identified were flavonols and

318 hydroxycinnamic acids. The majority of the flavonoids found in these varieties are

319 kaempferol glycosylated and acylated with different hydroxycinnamic acids. Quercetin and

320 isorhamnetin derivatives were also found. Kaempferol and quercetin are the most prevalent

321 flavonoids in the Brassicaceae family. Kaempferol is known to be a strong antioxidant and

322 quercetin also a potent free radical scavenger and is considered to be a protective against

323 cardiovascular disease. Cabbage is a well established crop at world level as cauliflower or

324 broccoli. Kale and leaf rape are minority crops in many parts of the world but they are a good

325 source of nutritive compounds and due to their rusticity (Rodriguez et al., 2005; Padilla et al.,

326 2007b) could be a good substitute of different Brassica species under hard climatic

327 conditions.

328

329 Acknowledgements

330 Research supported by the National Plan for Research and Development (AGL2009-09922)

331 and the Excma. Diputación Provincial de Pontevedra. Marta Francisco acknowledges a I3P

332 Fellowship from the CSIC. The authors thank Rosaura Abilleira and Susana Calvo for all the

333 invaluable help in the laboratory work.

334

335 


\section{References}

337

338

339

340

341

342

343

344

345

346

347

348

349

350

351

352

353

354

355

356

357

358

359

360

361

362

363

364

365

366

367

368

369

370

371

372

373

374

375

376
Ayaz FA, S Hayirlioglu-Ayaz, S Alpay-Karaoglu, J Gruz, K Valentova, J Ulrichova, and M Strnad. 2008. Phenolic acid contents of kale (Brassica oleraceae L. var. acephala DC.) extracts and their antioxidant and antibacterial activities. Food Chem. 107:19-25.

Bennett RN, EAS Rosa, FA Mellon, and PA Kroon. 2006. Ontogenic profiling of glucosinolates, flavonoids, and other secondary metabolites in Eruca sativa (salad rocket), Diplotaxis erucoides (wall rocket), Diplotaxis tenuifolia (wild rocket), and Bunias orientalis (Turkish rocket). J. Agric. Food Chem. 54:4005-4015.

Bennett RN, FA Mellon, N Foidl, JH Pratt, MS Dupont, L Perkins, and PA Kroon. 2003. Profiling glucosinolates and phenolics in vegetative and reproductive tissues of the multi-purpose trees Moringa oleifera L. (horseradish tree) and Moringa stenopetala L. J. Agric. Food Chem. 51:3546-3553.

Cartea ME, and P Velasco. 2008. Glucosinolates in Brassica foods: Bioavailability in food and significance for human health. Phytochem. Rev. 7:213-229.

Cartea ME, VM Rodriguez, A de Haro, P Velasco, and A Ordas. 2008a. Variation of glucosinolates and nutritional value in nabicol (Brassica napus pabularia group). Euphytica 159:111-122.

Cartea ME, P Velasco, S Obregon, G Padilla, and A de Haro. 2008b. Seasonal variation in glucosinolate content in Brassica oleracea crops grown in northwestern Spain. Phytochemistry 69:403-10.

Cermak R, S Landgraf, and S Wolffram. 2003. The bioavailability of quercetin in pigs depends on the glycoside moiety and on dietary factors. J. Nutr. 133:2802-2807.

Clarke JD, RH Dashwood, and E Ho. 2008. Multi-targeted prevention of cancer by sulforaphane. Cancer Lett. 269:291-304.

Duthie GG, SJ Duthie, and JAM Kyle. 2000. Plant polyphenols in cancer and heart disease: implications as nutritional antioxidants. Nutrition Research Reviews 13:79-106.

Fabre N, V Poinsot, L Debrauwer, C Vigor, J Tulliez, I Fouraste, and C Moulis. 2007. Characterisation of glucosinolates using electrospray ion trap and electrospray quadrupole time-of-flight mass spectrometry. Phytochem. Anal. 18:306-319.

Ferreres F, R Llorach, and A Gil-Izquierdo. 2004. Characterization of the interglycosidic linkage in di-, tri-, tetra- and pentaglycosylated flavonoids and differentiation of positional isomers by liquid chromatography/electrospray ionization tandem mass spectrometry. J. Mass Spectrom. 39:312-321.

Ferreres F, C Sousa, V Vrchovska, P Valentao, JA Pereira, RM Seabra, and PB Andrade. 2006. Chemical composition and antioxidant activity of tronchuda cabbage internal leaves. Eur. Food Res. Technol. 222:88-98.

Ferreres F, P Valentao, JA Pereira, A Bento, A Noites, RM Seabra, and PB Andrade. 2008. HPLC-DAD-MS/MS-ESI screening of phenolic compounds in Pieris brassicae L. reared on Brassica rapa var. rapa L. J. Agric. Food Chem. 56:844-853.

Ferreres F, P Valentao, R Llorach, C Pinheiro, U Cardoso, JA Pereira, C Sousa, RM Seabra, and PB Andrade. 2005. Phenolic compounds in external leaves of tronchuda cabbage (Brassica oleracea L. var. costata DC). J. Agric. Food Chem. 53:2901-2907.

Francisco M, DA Moreno, ME Cartea, F Ferreres, C Garcia-Viguera, and P Velasco. 2009. Simultaneous identification of glucosinolates and phenolic compounds in a representative collection of vegetable Brassica rapa. J Chromatogr A 1216:6611-9.

Jahangir M, HK Kim, YH Choi, and R Verpoorte. 2009. Health-Affecting Compounds in Brassicaceae. Comprehensive Reviews in Food Science and Food Safety 8:31-43.

Jeffery EH, and M Araya. 2009. Physiological effects of broccoli consumption. Phytochem. Rev. 8:283-298. 
Kokkonen PS, J Vandergreef, WMA Niessen, UR Tjaden, GJ Tenhove, and G Vandewerken. 1991. Identification of intact glucosinolates using direct coupling of high-performance Liquid-Chromatography with continuous-flow frit fast-atom-bombardment tandem mass-spectrometry. Biological Mass Spectrometry 20:259-267.

Kushad MM, AF Brown, AC Kurilich, JA Juvik, BP Klein, MA Wallig, and EH Jeffery. 1999. Variation of glucosinolates in vegetable crops of Brassica oleracea. J. Agric. Food Chem. 47:1541-1548.

Llorach R, JC Espin, FA Tomas-Barberan, and F Ferreres. 2003a. Valorization of cauliflower (Brassica oleracea L. var. botrytis) by-products as a source of antioxidant phenolics. J. Agric. Food Chem. 51:2181-2187.

Llorach R, A Gil-Izquierdo, F Ferreres, and FA Tomas-Barberan. 2003b. HPLC-DADMS/MS ESI characterization of unusual highly glycosylated acylated flavonoids from cauliflower (Brassica oleracea L. var. botrytis) agroindustrial byproducts. J. Agric. Food Chem. 51:3895-3899.

Martens DA. 2002. Identification of phenolic acid composition of alkali-extracted plants and soils. Soil Sci. Soc. Am. J. 66:1240-1248.

Mellon FA, RN Bennett, B Holst, and G Williamson. 2002. Intact glucosinolate analysis in plant extracts by programmed cone voltage electrospray LC/MS: Performance and comparison with LC/MS/MS methods. Anal. Biochem. 306:83-91.

Mithen R, K Faulkner, R Magrath, P Rose, G Williamson, and J Marquez. 2003. Development of isothiocyanate-enriched broccoli, and its enhanced ability to induce phase 2 detoxification enzymes in mammalian cells. Theor. Appl. Genet. 106:727-734.

Olsen H, K Aaby, and GIA Borge. 2009. Characterization and Quantification of Flavonoids and Hydroxycinnamic Acids in Curly Kale (Brassica oleracea L. Convar. acephala Var. sabellica) by HPLC-DAD-ESI-MSn. J. Agric. Food Chem. 57:2816-2825.

Padilla G, ME Cartea, and A Ordas. 2007a. Comparison of several clustering methods in grouping kale landraces. J. Am. Soc. Hort. Sci. 132:387-395.

Padilla G, ME Cartea, P Soengas, and A Ordas. 2007b. Characterization of fall and spring plantings of Galician cabbage germplasm for agronomic, nutritional, and sensory traits. Euphytica 154:63-74.

Padilla G, ME Cartea, P Velasco, A de Haro, and A Ordas. 2007c. Variation of glucosinolates in vegetable crops of Brassica rapa. Phytochemistry 68:536-545.

Picoaga A, ME Cartea, P Soengas, L Monetti, and A Ordas. 2003. Resistance of kale populations to lepidopterous pests in northwestern Spain. J. Econ. Entomol. 96:143147.

Rochfort SJ, M Imsic, R Jones, VC Trenerry, and B Tomkins. 2006. Characterization of flavonol conjugates in immature leaves of pak choi [Brassica rapa $\mathrm{L}$. Ssp chinensis $\mathrm{L}$. (Hanelt.)] by HPLC-DAD and LC-MS/MS. J. Agric. Food Chem. 54:4855-4860.

Rochfort SJ, VC Trenerry, M Imsic, J Panozzo, and R Jones. 2008. Class targeted metabolomics: ESI ion trap screening methods for glucosinolates based on MSn fragmentation. Phytochemistry 69:1671-1679.

Rodriguez VM, ME Cartea, G Padilla, P Velasco, and A Ordas. 2005. The nabicol: A horticultural crop in northwestern Spain. Euphytica 142:237-246.

Romani A, P Vignolini, L Isolani, F Ieri, and D Heimler. 2006. HPLC-DAD/MS characterization of flavonoids and hydroxycinnamic derivatives in turnip tops (Brassica rapa L. subsp sylvestris L.). J. Agric. Food Chem. 54:1342-1346.

Soengas P, ME Cartea, P Velasco, G Padilla, and A Ordas. 2008. Morphologic and agronomic diversity of Brassica napus crops. J. Am. Soc. Hort. Sci. 133:48-54. 
433 Sousa C, M Taveira, P Valentao, F Fernandes, JA Pereira, L Estevinho, A Bento, F Ferreres, RM Seabra, and PB Andrade. 2008. Inflorescences of Brassicacea species as source of bioactive compounds: A comparative study. Food Chem. 110:953-961.

Traka M, and R Mithen. 2009. Glucosinolates, isothiocyanates and human health. Phytochem. Rev. 8:269-282.

Vallejo F, FA Tomas-Barberan, and F Ferreres. 2004. Characterisation of flavonols in broccoli (Brassica oleracea L. var. italica) by liquid chromatography-UV diode-array detection-electrospray ionisation mass spectrometry. J. Chromatogr. 1054:181-193.

Velasco P, P Soengas, M Vilar, ME Cartea, and M del Rio. 2008. Comparison of glucosinolate profiles in leaf and seed tissues of different Brassica napus crops. J. Am. Soc. Hort. Sci. 133:551-558.

Vilar M, ME Cartea, G Padilla, P Soengas, and P Velasco. 2008. The potential of kales as a promising vegetable crop. Euphytica 159:153-165. 
Table 1.List of identified glucosinolates with the corresponding retention times and MS data in extracts of leaf rape (B. napus pabularia group), cabbage (B. oleracea capitata group), and kale crops (B. oleracea acephala group)..

\begin{tabular}{|c|c|c|c|c|c|c|c|}
\hline Code & Compound & $\begin{array}{l}\mathrm{Rt} \\
(\min )\end{array}$ & $\mathrm{m} / \mathrm{z}[\mathrm{M}-\mathrm{H}]^{-}$ & $\mathrm{MS}^{2}[\mathrm{M}-\mathrm{H}]^{-} m / z(\%)$ & Leaf rape & Kale & Cabbage \\
\hline GIB & Glucoiberin & 4.8 & 422 & $358(100), 342(1), 291(2), 275(3), 259(5), 195(2), 180(6)$ & $\mathrm{X}$ & $\mathrm{X}$ & $\mathrm{X}$ \\
\hline PRO & Progoitrin & 5.9 & 388 & $332(29), 308(12), 301(17), 275(40), 259(100), 240(18)$ 210(78), 195(14), 192(24), 154(16),136(42), 130(30) & $\mathrm{X}$ & - & - \\
\hline SIN & Sinigrin & 6.6 & 358 & 278(2), 275(7), 259(100), 241(28), 195(4), 180(3), 162(8), 135(2), 116(5) & $\mathrm{X}$ & $\mathrm{X}$ & $\mathrm{X}$ \\
\hline GRA & Glucoraphanin & 7.4 & 436 & $420(6), 372(100), 356(1), 291(2), 275(1), 259(3), 194(2), 162(4)$ & $\mathrm{X}$ & $\mathrm{X}$ & $\mathrm{X}$ \\
\hline GNL & Gluconapoleiferin & 12.3 & 402 & $306(53), 275(20), 259(100), 240(7), 225(10), 215(24), 195(10), 163(13), 160(9), 145(18), 140(23), 120(9)$ & $\mathrm{X}$ & - & - \\
\hline GNA & Gluconapin & 12.5 & 472 & 292(4), 275(30), 259(100), 241(37), $227(9), 195(25), 176(8), 139(11), 130(10)$ & $\mathrm{X}$ & - & - \\
\hline 4-OHGBS & 4-Hydroxiglucobrassicin & 13.1 & 463 & $403(2), 383(10), 365(6), 300(6), 285(73), 267(100), 259(17), 240(25), 220(17), 169(30), 160(23), 132(5)$ & $\mathrm{X}$ & $\mathrm{X}$ & $\mathrm{X}$ \\
\hline GBN & Glucobrassicanapin & 15.7 & 386 & $306(4), 275(21), 259(100), 241(33), 208(12), 195(6), 163(4), 144(18)$ 139(8) & $\mathrm{X}$ & - & - \\
\hline GBS & Glucobrassicin & 16.8 & 447 & $367(22), 291(6), 275(34), 259(100), 251(17), 241(11), 224(3), 205(28), 195(11), 144(9)$ & $\mathrm{X}$ & $\mathrm{X}$ & $\mathrm{X}$ \\
\hline GST & Gluconasturtiin & 19.5 & 422 & $342(9), 275(24), 259(100), 244(7), 229(8), 195(13), 180(24), 169(1), 163(5), 145(4), 140(6), 119(4)$ & $\mathrm{X}$ & $\mathrm{X}$ & $\mathrm{X}$ \\
\hline 4-MGBS & 4-Methoxyglucobrassicin & 20.4 & 477 & $397(25), 299(14), 291(69), 275(98), 259(62), 241(80), 235(100), 198(80), 195(16), 144(70)$ & - & $\mathrm{X}$ & $\mathrm{X}$ \\
\hline NGBS & Neoglucobrassicin & 23.5 & 477 & $447(68), 446(100), 429(16), 385(5), 273(12), 259(16), 241(26), 224(4), 205(5)$ & $\mathrm{X}$ & $\mathrm{X}$ & $\mathrm{X}$ \\
\hline
\end{tabular}


Table 2. Data of glycosilated flavonoids from saponificated extract (compounds 1-9) and acylated flavonoids from native extracts of leaf rape (B. napus pabularia group), cabbage (B. oleracea capitata group), and kale crops (B. oleracea acephala group). (compounds 10-22).

\begin{tabular}{|c|c|c|c|c|c|c|c|c|c|}
\hline Peak & Compound & $\begin{array}{l}\mathrm{Rt} \\
(\mathrm{min})\end{array}$ & $\begin{array}{l}\text { UV } \\
(\mathrm{nm})\end{array}$ & $\begin{array}{l}{[\mathrm{M}-\mathrm{H}]^{-}} \\
(\mathrm{m} / z)\end{array}$ & $\mathrm{MS}^{2}[\mathrm{M}-\mathrm{H}]^{-} m / z(\%)$ & $\mathrm{MS}^{3}$ & $\begin{array}{l}\text { Leaf } \\
\text { rape }\end{array}$ & Kale & Cabbage \\
\hline 1 & Querc-3-O-shop-7-O-glc & 16.9 & $255,267 \mathrm{sh}, 351$ & 787 & $625(100), 463(5), 301(3)$ & $463(23), 445(21), 300(100)$ & - & $\mathrm{X}$ & $\mathrm{X}$ \\
\hline 2 & Kaempf-3-O-triglc-7-O-glc & 17.0 & $266,316 \mathrm{sh}, 348$ & 933 & $771(100)$ & $489(15), 429(19), 285(100)$ & $\mathrm{X}$ & $\mathrm{X}$ & $\mathrm{X}$ \\
\hline 3 & Kaempf-3-O-soph-7-O-glc & 17.4 & $266.317 \mathrm{sh}, 347$ & 771 & $609(100)$ & $489(25), 429(21), 285(100)$ & $\mathrm{X}$ & $\mathrm{X}$ & $\mathrm{X}$ \\
\hline 4 & Kaempf-3,7-di-O-glc & 19.6 & $265,317 \mathrm{sh}, 347$ & 609 & $488(8), 447(100), 285(34)$ & $285(100)$ & $\mathrm{X}$ & $\mathrm{X}$ & $\mathrm{X}$ \\
\hline 5 & Isorhmnt-3,7-di- $O$-glc & 19.9 & $255,267 \mathrm{sh}, 352$ & 639 & 519(12), 477(100), 315(19) & $314(100)$ & $\mathrm{X}$ & - & - \\
\hline 6 & Querc-3-O-soph & 20.5 & - & 625 & $463(10), 445(51), 300(100)$ & - & - & $\mathrm{X}$ & $\mathrm{X}$ \\
\hline 7 & Kaempf-3-O-diglc & 22.8 & 266,297 sh, 347 & 609 & $447(100), 285(80)$ & $285(100)$ & - & $\mathrm{X}$ & $\mathrm{X}$ \\
\hline 8 & Kaempf-3-O-soph & 27.4 & $266,297 \mathrm{sh}, 347$ & 609 & $447(21), 429(65), 285(100)$ & - & - & $\mathrm{X}$ & $\mathrm{X}$ \\
\hline 9 & Kaempf-7-O-glc & 28.1 & 266,318 sh, 367 & 447 & $285(100)$ & - & $\mathrm{X}$ & $\mathrm{X}$ & $\mathrm{X}$ \\
\hline 10 & Querc-3-O(caffeoyl)-shop-7-O-glc & 17.8 & 253,269 sh, 299sh, 337 & 949 & 787(100), 625(50) & $625(100)$ & $\mathrm{X}$ & $\mathrm{X}$ & $\mathrm{X}$ \\
\hline 11 & Kaempf-3-O-(methoxycaffeoyl)-soph-7-O-glc & 18.4 & 269,331 & 963 & $801(100), 609(7)$ & $609(100), 285(12)$ & $\mathrm{X}$ & $\mathrm{X}$ & $\mathrm{X}$ \\
\hline 12 & Kaempf-3-O-(caffeoyl)-soph-7-O-glc & 18.6 & 269,331 & 933 & 771(100), 609(7) & $609(100), 285(10)$ & $\mathrm{X}$ & $\mathrm{X}$ & $\mathrm{X}$ \\
\hline 13 & Querc-3-O-(sinapyl)-shop-7-O-glc & 18.8 & 270,337 & 993 & $831(100), 787(60), 625(65)$ & $625(100)$ & $\mathrm{X}$ & $\mathrm{X}$ & $\mathrm{X}$ \\
\hline 14 & Kaempf-3-O-(sinapoyl)-soph-7-O-glc & 19.6 & 269,331 & 977 & $815(100), 609(3)$ & $609(100), 285(10)$ & $\mathrm{X}$ & $\mathrm{X}$ & $\mathrm{X}$ \\
\hline 15 & Kaempf-3-O-(feruloyl)-soph-7-O-glc & 20.0 & Coeluting with 16 & 947 & $785(100), 609(6)$ & $609(5)$ & $\mathrm{X}$ & $\mathrm{X}$ & $\mathrm{X}$ \\
\hline 16 & Kaempf-3-O-(p-coumaroyl)-soph-7-O-glc & 20.1 & Coeluting with 15 & 917 & 755(100), 609(5), & - & $\mathrm{X}$ & $\mathrm{X}$ & $\mathrm{X}$ \\
\hline 17 & Kaempf-3-O-(caffeoyl)-soph-7-O-glc (isomer) & 20.8 & 269,331 & 933 & $771(100), 609(9)$ & $609(100)$ & $\mathrm{X}$ & - & - \\
\hline 18 & Kaempf-3-O-(p-coumaroyl)-soph & 23.4 & 269,317 & 755 & $609(100), 429(1), 284(15)$ & $429(35), 285(100)$ & - & $\mathrm{X}$ & $\mathrm{X}$ \\
\hline 19 & Kaempf-3-O-(methoxycaffeoyl)-soph & 24.3 & 268,330 & 801 & $609(100), 429(5), 285(10)$ & $429(25), 285(100)$ & $\mathrm{X}$ & $\mathrm{X}$ & $\mathrm{X}$ \\
\hline 20 & Kaempf-3-O-(caffeoyl)-soph & 24.7 & 269,330 & 771 & $609(100), 429(4), 285(9)$ & $428(34), 285(100)$ & $\mathrm{X}$ & $\mathrm{X}$ & $\mathrm{X}$ \\
\hline 21 & Querc-3-O-(feruloyl)-soph & 25.1 & - & 801 & $625(100), 445(5), 301(4)$ & $445(15), 301(100)$ & $\mathrm{X}$ & $\mathrm{X}$ & $\mathrm{X}$ \\
\hline 22 & Kaempf-3-O-(sinapoyl)-soph & 25.6 & 269,330 & 815 & $609(100), 429(3), 285(9)$ & $429(30), 285(100)$ & $\mathrm{X}$ & $\mathrm{X}$ & $\mathrm{X}$ \\
\hline
\end{tabular}


Table 3. Data of hydroxycinnamic acids from extracts of leaf rape (B. napus pabularia group), cabbage (B. oleracea capitata group), and kale crops (B. oleracea acephala group).

\begin{tabular}{|c|c|c|c|c|c|c|c|c|c|}
\hline Peak & Compound & $\begin{array}{l}\mathrm{Rt} \\
(\mathrm{min})\end{array}$ & $\begin{array}{l}\text { UV } \\
(\mathrm{nm})\end{array}$ & $\begin{array}{l}{[\mathrm{M}-\mathrm{H}]^{-}} \\
(\mathrm{m} / \mathrm{z})\end{array}$ & $\mathrm{MS}^{2}[\mathrm{M}-\mathrm{H}]^{-} m / z(\%)$ & $\mathrm{MS}^{3}[(\mathrm{M}-\mathrm{H}) \rightarrow(\mathrm{M}-\mathrm{H}-224)]^{-}$ & Leaf rape & Kale & Cabbage \\
\hline 3CQAc & 3-Caffeoyl quinic acid & 17.3 & $295 \mathrm{sh}, 325$ & 353 & $191(100), 179(62)$ & - & $\mathrm{X}$ & $\mathrm{X}$ & $\mathrm{X}$ \\
\hline 3pCoQAc & 3-p-Coumaroyl quinic acid & 19.1 & 311 & 337 & $191(7), 179(100)$ & - & $\mathrm{X}$ & $\mathrm{X}$ & $\mathrm{X}$ \\
\hline 4CQAc & 4-Caffeoyl quinic acid & 19.6 & $295 \mathrm{sh}, 326$ & 353 & $191(16), 179(53), 173(100), 135(12)$ & - & - & $\mathrm{X}$ & $\mathrm{X}$ \\
\hline SG & Sinapylglucoside & 20.5 & 329 & 285 & $291(100 \%), 223(85 \%)$ & - & $\mathrm{X}$ & $\mathrm{X}$ & $\mathrm{X}$ \\
\hline 4FQAc & 4-Feruloyl quinic acid & 22.9 & 325 & 367 & $191(5), 173(3), 163(100), 119(5)$ & - & - & $\mathrm{X}$ & $\mathrm{X}$ \\
\hline SA & Sinapic acid & 27.3 & 329 & 223 & $208(35), 179(30), 164(100)$ & - & $\mathrm{X}$ & In traces & In traces \\
\hline $\mathbf{A}$ & 1,2-Disinapoylgentiobioside & 28.1 & 330 & 753 & $529(100), 223(1)$ & $223(100), 205(59)$ & $\mathrm{X}$ & $\mathrm{X}$ & $\mathrm{X}$ \\
\hline $\mathbf{B}$ & 1-Sinapoyl-2-feruloylgentiobioside & 28.7 & 330 & 723 & $529(11), 499(100), 259(4)$ & $259(28), 246(20), 217(53)$ & $\mathrm{X}$ & $\mathrm{X}$ & $\mathrm{X}$ \\
\hline $\mathbf{C}$ & 1,2,2'-Trisinapoylgentiobioside & 30.5 & 330 & 959 & $735(100)$ & $717(15), 529(100)$ & $\mathrm{X}$ & $\mathrm{X}$ & $\mathrm{X}$ \\
\hline $\mathbf{D}$ & 1,2'-Disinapoyl-2-feruloylgentiobioside & 31.2 & 330 & 929 & $735(4), 705(100)$ & $499(100)$ & $\mathrm{X}$ & $\mathrm{X}$ & $\mathrm{X}$ \\
\hline
\end{tabular}


Figure 1. Glucosinolate profile of leaf rape (B. napus pabularia group), cabbage (B. oleracea capitata group), and kale crops (B. oleracea acephala group).

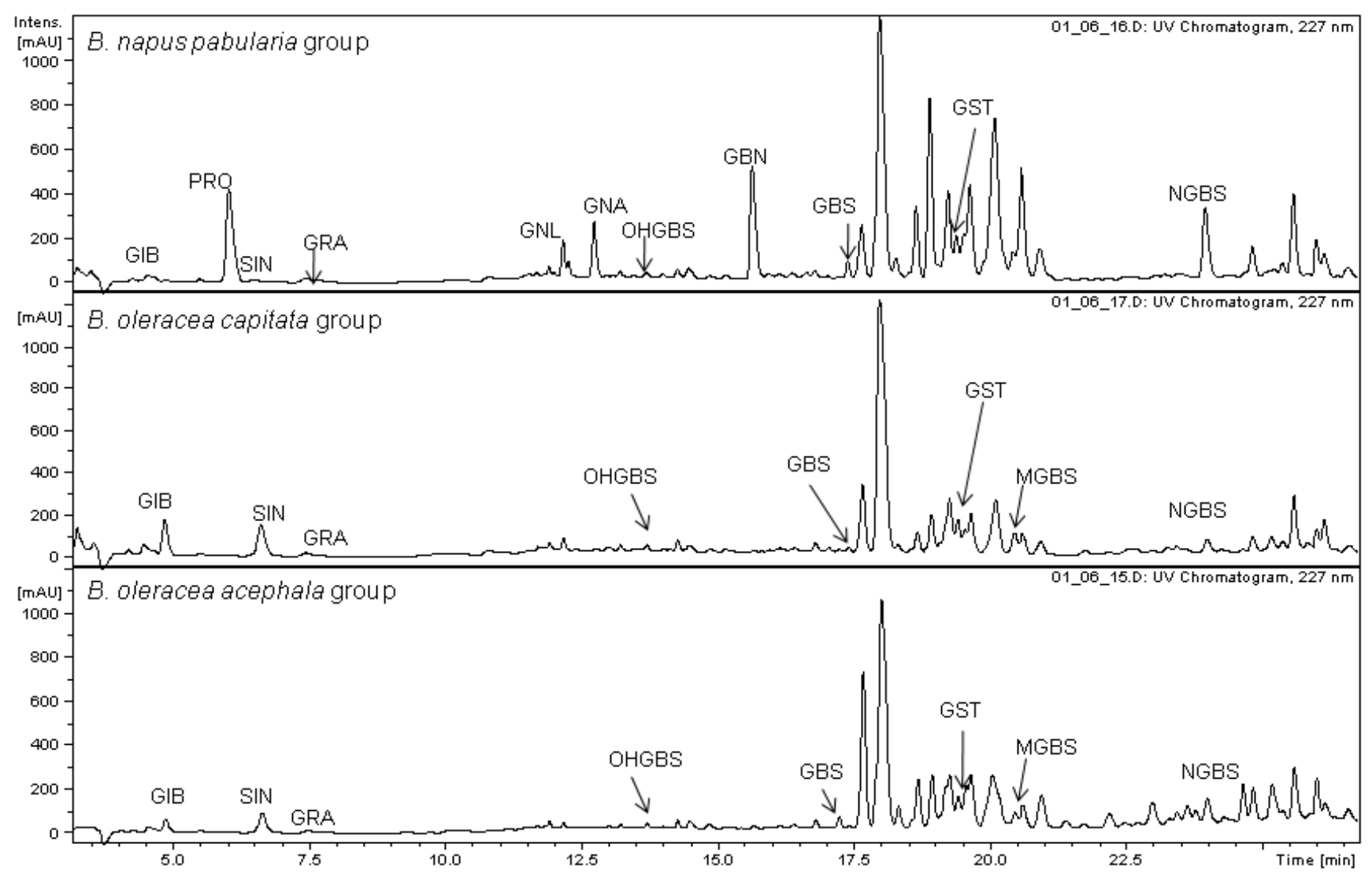


GIB= Glucoiberin. $\mathbf{P R O}=$ Progoitrin. $\mathbf{S I N}=$ Sinigrin. GRA=Glucoraphanin. GNL=Gluconapoleiferin. GNA=Gluconapin. 4-OHGBS=4-Hydroxiglucobrassicin. GBN=Glucobrassicanapin. GBS=Glucobrassicin. GST=Gluconasturtiin. 4-MGBS=4-Methoxyglucobrassicin. NGBS=Neoglucobrassicin. 
Figure 2. Phenolic profiles of leaf phenolics in rape (B. napus pabularia group), cabbage (B. oleracea capitata group), and kale (B. oleracea acephala group).

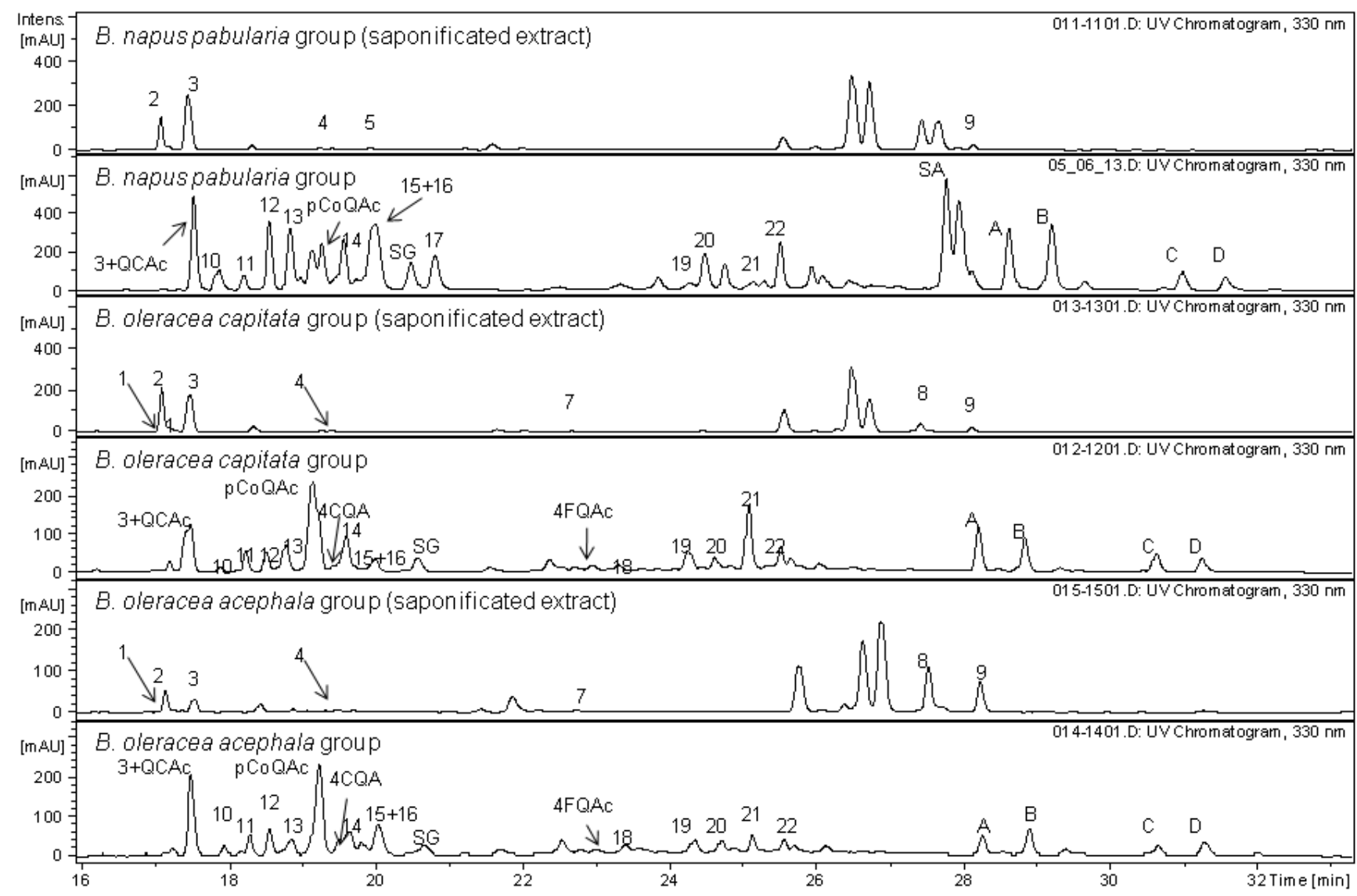


1=Querc-3-O-shop-7- $O$-glc. 2=Kaempf-3- $O$-triglc-7- $O$-glc. 3=Kaempf-3- $O$-soph-7- $O$-glc. 4=Kaempf-3,7-di- $O$-glc. 5=Isorhmnt-3,7-di- $O$-glc. 6=Querc-3- $O$-soph. 7=Kaempf-3- $O$-diglc. 8=Kaempf-3- $O$-soph. 9=Kaempf-7- $O$-glc. 10=Querc-3- $O$ (caffeoyl)-shop-7- $O$-glc. 11=Kaempf-3- $O$-(methoxycaffeoyl)-soph-7- $O$-glc. 12=Kaempf-3- $O$-(caffeoyl)-soph-7- $O$-glc. 13=Querc-3- $O$-(sinapyl)-shop-7- $O$-glc. 14=Kaempf-3- $O$-(sinapoyl)-soph-7- $O$-glc. 15=Kaempf-3-O-(feruloyl)-soph-7- $O$-glc . 16=Kaempf-3- $O$-(p-coumaroyl)-soph-7- $O$-glc. 17=Kaempf-3- $O$-(caffeoyl)-soph-7- $O$-glc (isomer). 18=Kaempf-3- $O$-(p-coumaroyl)-soph. 19=Kaempf-3- $O-$

(methoxycaffeoyl)-soph. 20=Kaempf-3- $O$-(caffeoyl)-soph. 21=Querc-3- $O$-(feruloyl)-soph. 22=Kaempf-3-O-(sinapoyl)-soph. 3CQAc=3-Caffeoyl quinic acid. $3 p \mathrm{CoQAc}=3-p$-Coumaroyl quinic acid. $4 \mathrm{CQAc}=4$-Caffeoyl quinic acid. $\mathbf{S G}=$ Sinapylglucoside. $4 \mathrm{FQAc}=4$-Feruloyl quinic acid. SA=Sinapic acid. $\mathbf{A}=1,2-$

Disinapoylgentiobioside. $\mathbf{B}=1$-Sinapoyl-2-feruloylgentiobioside. $\mathbf{C}=1,2,2$ '-Trisinapoylgentiobioside. $\mathbf{D}=1,2$ '-Disinapoyl-2-feruloylgentiobioside 